\title{
The Effect of Self-Efficacy Based Education on the Daily Care of Stroke Patients and its Implications with Counseling
}

\author{
Rizaldi Nanda Wiguna, Kiking Ritarwan, Nur Asnah Sitohang, M. \\ Harwansyah Putra Sinaga
}

\author{
Universitas Sumatera Utara, Medan-Indonesia \\ Email address: nandawiguna19@gmail.com
}

Submitted : 18-06-2021, Revised : 27-08-2021, Accepted : 26-11-2021

\begin{abstract}
Stroke patients generally experience daily self-care disorders due to old age (elderly), so that motor skills are low. One factor affecting the ability to take care of oneself every day and be motivated to be independent is self-efficacy. The purpose of this study was to analyze the effect of self-efficacy-based education on the daily self-care of stroke patients at the Haji Adam Malik General Hospital and its implications with counselling guidance. The type of research used is a quasi-experimental design using the nonequivalent control group prepost-test only design method. The population in this study were all ischemic stroke patients at Haji Adam Malik Hospital Medan and a sample of 36 people. Researchers provided educational interventions based on self-efficacy using visual media, discussions, motor skills training, and occupational exercises for three meetings per week with a duration of 30 minutes each session for six weeks. Data collection with primary and secondary data and analyzed by statistical test Paired Sample t-Test. The results showed an effect of self-efficacy-based education on the daily care of stroke patients at Haji Adam Malik Hospital Medan (p-value $=0.000<0.05$ ) such as motor function and improving their daily activities.
\end{abstract}

Keywords: Counseling; Daily care; Self-efficacy

\section{Introduction}

Stroke is a disease accompanied by a sudden decline in brain function and causes the cessation of life (Hachinski et al., 2019). Stroke is a common disease with consequences of death and illness. Stroke is one of the leading causes of permanent disability and death worldwide. The impact of a stroke can make sufferers experience psychological stress, anxiety, and even severe stress (Müller et al., 2021). According to the World Health Organization (WHO), about 15 million people suffera stroke every year, 5 million are permanently disabled, and 5 million people die. The incidenceof stroke increases rapidly with age, doubling after 55 years of age. In adults aged 35-44 years, the incidence of stroke is 30120 of 100,000 per year, and for those aged 65-74 years, the incidence is 670-970 of 100,000 per year. The prevalence of stroke in European countries and the United States ranges from $1.5 \%$ in Italy, $3 \%$ in the UK and the United States. In Asian countries, stroke prevalence has been reported in the range of 45-471 per 100,000 (Chen et al., 2020).

Almost all hospitals in Indonesia recorded a mortality rate of around $15.4 \%$. Stroke isthe leading cause of death in stroke patients. While in 2013, the prevalence of stroke was around $7 \%$, while in 2018, there was an increase of $10.9 \%$. Health workers have diagnosed stroke disease as much as $57.9 \%$. With increasing age, the prevalence of stroke increases. The highest stroke was aged over 75 years $(50.2 \%)$, and the lowest was at the age of 15-24 years $(0.6 \%)$ (Riskesdas, 2018). Data obtained from the Haji Adam Malik General Hospital (RSUP HAM), the number of stroke patients in January - December 2019 was recorded as 520 inpatients and 108 outpatients. Stroke sufferers with older age are usually unable/independently to take care of themselves (Williams, 2021). Stroke patients who are not independent feel alienated and became a burden to their families (Mairami et al., 2020). According to (Torrisi et al., 2018), self-efficacy influences the daily care of stroke patients. 
Not only that, self-efficacy determines someone's goals to achieve something including predicting various events that will be faced (Rafiola et al., 2020). It means self-efficacy can help the ability of stroke patients in their daily care (Szczepańska-Gieracha \& Mazurek, 2020). One study said stroke survivors experienced feelings of fear of the absence of interpersonal acceptance and rejection(López-Espuela et al., 2018). Anxiety is also associated with separation and loss which gives rise to specific weaknesses. In addition, other studies say stroke patients have a threat to integrity which includes physiological inability or decreased ability to perform activities of daily living (Li et al., 2019).

Supported by research that finds patients who have been diagnosed with a stroke, the trigger factors are factors experienced by individuals, both internal and external. Internal factors are fear of disability, death, fear of losing their job, being dependent on their family. While the external factors are the new environment, ADL equipment such as wheelchairs, crutches and sticks that are foreign and health workers (Amieva et al., 2019). In the psychological maintenance of stroke, there are several treatments including pharmacological and non-pharmacological therapy. Pharmacological therapy usually uses anxiolytic drugs such as diazepam, clobazam, bromazepam, lorazepam, buspirone HCL, meprobamate and alprazolam. One of the non-pharmacological therapies is counselling

Stroke patients also need mental health services such as counselling guidance. Therefore, the purpose of this study was to analyze the effect of self-efficacy-based education on the daily self-care of stroke patients at Haji Adam Malik General Hospital and its implications with counselling guidance.

\section{Methods}

This quantitative study uses a quasi-experimental design with a nonequivalent control group pre-posttest only design method. The sampling technique in this study was carried out by non-probability sampling type of convenience sampling with 36 people in the experiment group only. This research was conducted in February-March 2021. Researchers provided an intervention, namely education based on self-efficacy, 30 minutes per day, three days a week for six weeks. The research data was obtained from filling out the SSEQ and Barthel Index questionnaires at more than 0.75 in its validity. Ethical approval to conduct this research was obtained from the Ethics Committee for the Implementation of Health Research, University of North Sumatra, Faculty of Medicine NO:141/KEP/USU/2021.

\section{Results and Discussion}

The characteristics of the respondents studied in this study include gender, age, education, marital status, type of stroke, and status of a stroke at Haji Adam Malik Hospital Medan can be seen in Table 1 . 
Table 1.

Frequency Distribution of Respondents' Characteristics

\begin{tabular}{|c|c|c|c|c|}
\hline \multirow[b]{2}{*}{ No. } & \multirow{2}{*}{\multicolumn{2}{|c|}{ Variable }} & \multicolumn{2}{|c|}{ Characteristics of Respondents } \\
\hline & & & $\begin{array}{l}\text { Frequency } \\
\text { (f) }\end{array}$ & $\begin{array}{l}\text { Percentage } \\
(\%)\end{array}$ \\
\hline \multirow[t]{4}{*}{1} & & Sex & & \\
\hline & & Male & 22 & 61,1 \\
\hline & & Female & 14 & 38,9 \\
\hline & & Total & 36 & 100,0 \\
\hline \multirow[t]{8}{*}{2} & & Age & & \\
\hline & & $26-35$ years old & 3 & 8,3 \\
\hline & & $36-45$ years old & 5 & 13,9 \\
\hline & & $46-55$ years old & 14 & 38,9 \\
\hline & & $56-65$ years & 10 & 27,8 \\
\hline & & More than 65 & 4 & 11,1 \\
\hline & years old & & & \\
\hline & & Total & 36 & $\mathbf{1 0 0 , 0}$ \\
\hline \multirow[t]{8}{*}{3} & & Educational & & \\
\hline & Backgro & und & & \\
\hline & & Junior & 8 & 22,2 \\
\hline & School & & & \\
\hline & & Senior & 26 & 72,2 \\
\hline & School & & & \\
\hline & & Higher School & 2 & 11,1 \\
\hline & & Total & 36 & $\mathbf{1 0 0 , 0}$ \\
\hline \multirow[t]{5}{*}{4} & & Marital Status & & \\
\hline & & Married & 5 & 13,9 \\
\hline & & Single & 5 & 13,9 \\
\hline & & Widow/Widower & 23 & 63,9 \\
\hline & & Total & 8 & 22,2 \\
\hline \multirow[t]{4}{*}{5} & & Kinds of Stroke & & \\
\hline & & Hemorrhagic & 0 & 0,0 \\
\hline & & Ischemic & 36 & 100,0 \\
\hline & & Total & 36 & 100,0 \\
\hline \multirow[t]{4}{*}{6} & & Stroke Attack & & \\
\hline & & Fisrt Stroke & 34 & 94,4 \\
\hline & & Sequel Stroke & 2 & 5,6 \\
\hline & & Total & 36 & 100,0 \\
\hline
\end{tabular}

Based on table 1, it can be seen that the gender of the respondents is male, primarily as many as 22 people $(61.1 \%)$. The data of this study are similar to the results of the study of Chaudhary et al. (2021) in ischemic patients in the United States, which shows that the number of men is more than women. Keller et al. (2018) stated that the prevalence of ischemic stroke in men is higher than in women ( 372 vs 340 out of 100,000 citizens). More Keller et al. (2018) mentions that the factor that causes men to have a higher incidence of ischemic stroke is due to atrial thrombus factor where the blood flow velocity is higher low in the left atrium, while the left atrial diameter is larger in men. The age of the respondents is mainly the early elderly aged $46-55$ years as many as 14 people $(38.9 \%)$. The age of the youngest respondent is 26 years old while the oldest age is $>65$ years. The results of this study are almost the same as studies in the United States which showed that ischemic stroke patients 
were aged between 44-48 years with an average age of 50 years (Maksimovich, 2021). A study conducted by (Roy-O'Reilly \& McCullough, 2018) also concluded that ischemic stroke is more common in men at the age of 53 years and women at the age of 48 years.

The respondents' education is primarily high school education as many as 26 people (72.2\%). Respondent education is used as a reference for determining the respondent's ability to understand self-efficacy-based educational interventions. The results of research observations show that the respondent's education affects the ability respondents in understanding self-efficacy based educational interventions. Respondents who have higher education are easier to understand educational interventions based on self-efficacy compared to respondents who have low education. The results of this study are almost the same as those of (Brouwer-Goossensen et al., 2018) which showed that acute ischemic stroke patients with an average high school education of 191 people (59\%).

The marital status of the respondents was mostly married as many as 23 people (63.9\%), this is related to the average age of respondents who experienced ischemic stroke is included in the category of married age. The research results by (Kawajiri et al., 2019)stated that the age of child marriage in Indonesiais mostly under 18 years. As many as $25.8 \%$ of parents and $26.0 \%$ of adolescents agree that a woman is ready to marry once she starts menstruating. The type of stroke of the respondents is ischemic stroke as many as 36 people $(100 \%)$, and the status of the first stroke of the respondent is 34 people $(94.4 \%)$. When conducting research in the inpatient unit, Rindu A Haji Adam Malik Hospital Medan found that the number of patients who had ischemic stroke was higher than the number of patients who had hemorrhagic stroke. This is following the research of (Denny et al., 2017), which states that the most common stroke prevalence in Indonesia is ischemic stroke, which is $87 \%$. (Volz et al., 2019)stated that patients were admitted within the first 24 hours after symptoms, while $6.7 \%$ of patients reported seven days or more after the onset of stroke symptoms. The results of self-efficacy before and after an educational intervention based on self-efficacy in stroke patients at Haji Adam Malik Hospital Medan can be seen in Table 2.

Table 2.

Self-Efficacy Before and After Self-Efficacy-Based Educational Interventionsin Stroke Patients

\begin{tabular}{|c|c|c|c|c|c|}
\hline \multirow[b]{2}{*}{ No } & \multirow[b]{2}{*}{ Self Efficacy } & \multicolumn{2}{|c|}{ Before } & \multicolumn{2}{|c|}{ After } \\
\hline & & $f$ & $(\%)$ & $\mathbf{f}$ & $\%$ \\
\hline 1 & Tall & 1 & 2,8 & 29 & 80,6 \\
\hline 2 & Currently & 14 & 38,9 & 7 & 19,4 \\
\hline 3 & Low & 21 & 58,3 & 0 & 0 \\
\hline & Total & 36 & 100 & 36 & 100 \\
\hline
\end{tabular}

Based on table 2, it can be seen that the self-efficacy before the educational intervention based on self-efficacy was mostly with low self-efficacy as many as 21 people $(58.3 \%)$, moderate efficacy 14 people (38.9\%), and High efficacy only one person $(2,8 \%)$. However, the study results after being given an educational intervention based on selfefficacy showed that most of the respondents had high self-efficacy, namely 29 people (80.6\%), and respondentswith moderate self-efficacy were seven people (19.4\%). According to (Ninuk et al., 2020), high self-efficacy effectively increases individual commitment in carrying out an activity and consequently leads to greater personal independence in carrying out daily self-care. According to (Wilhelm et al., 2020), self-efficacy can improve daily selfcare. Stroke patients who are independent in performing daily self-care are influenced by two 
elements, namely external and internal. External elements (family support, the existence of health facilities and socio-economic capabilities) while internal (age, stroke severity, and selfefficacy).

Usually, people who have high self-efficacy, easy to rise from adversity and have a high commitment to achieve something (Asayesh \& Vakili, 2020). Self-efficacy greatly influences a person in determining goals to achieve something, including being able to predict various events that will be faced (Shiau et al., 2020). Self-care in stroke patients includes a person's ability to optimize health status related to stroke experienced, such as the fulfilment of ADL, need for treatment therapy (Oh et al., 2021). Independent patients are patients who perform ADL independently without help from others. The research results of (Seneviratne $\&$ Anuruddhika, n.d.)show that patients who are declared to have recovered from stroke are patients who can independently fulfil the ADL.

Daily self-care before and after an educational intervention based on self-efficacy in stroke patients at Haji Adam Malik Hospital Medan can be seen in Table 3.

Table 3.

Daily Care Before and After Self-Efficacy-Based Educational Interventionsfor Stroke Patients

\begin{tabular}{llllll}
\hline No & Daily Care & \multicolumn{2}{c}{ Before } & \multicolumn{2}{l}{ After } \\
\hline & & $\mathrm{f}$ & $\%$ & $\mathrm{~F}$ & $\%$ \\
\hline 1 & Heavy Addiction & 11 & 30,6 & 9 & 25,0 \\
\hline 2 & Total Addiction & 25 & 69,3 & 1 & 2,8 \\
\hline 3 & Independet & & & 5 & 13,9 \\
\hline 4 & Mild Addiction & & & 4 & 11,1 \\
\hline 5 & Moderate Addiction & & & 17 & 47,2 \\
\hline & Total & 36 & 100 & 36 & 100 \\
\hline
\end{tabular}

Based on table 3, it can be seen that daily self-care before the education intervention based on self-efficacy was mainly with a total dependence of 25 people (69.3\%) and severe dependence 11 people $(69.3 \%)$. The results of self-care research after the intervention showed that respondents with moderate care were 17 people $(47.2 \%)$, mild dependence four people $(11.1 \%)$, independent five people $(13.9 \%)$, total dependence was only one person $(2,8 \%)$, heavy dependency nine people $(25.0 \%)$. The type of intervention that the researchers did was education based on self-efficacy in stroke patients at Haji Adam Malik Hospital, Medan.

According to Appalasamy et al. (2018), the risk factors for stroke that are continuously uncontrolled can lead to unexpected recurrent strokes. Various beliefs regarding individual illness and perceptions complicate one's mind towards good health and a meaningful quality of life. Patient education through video narration has proven to be useful in encouraging positive behavioural changes towards controlling stroke risk factors. The intervention is very innovative because it combines health beliefs, motivation, and role models to trigger self-efficacy in maintaining disease and better management of healthy behaviour. Therefore, video-based educational materials can be an effective educational tool to increase knowledge and encourage healthy behaviour in hospitalized stroke patients.Research conducted by Denny et al. (2017) states that video-based educational interventions have been used for other chronic diseases to increase knowledge and encourage changes in health behaviour. Video-based education has proven to be more effective than written materials in increasing knowledge and modifying health behaviours. The results to research conducted by S. Diz \& M. Prieto (2016), virtual reality education interventions are 
used in rehabilitation or physical therapy and have been shown to improve motor function in the upper limbs and improve daily activities in stroke patients. To see the effect of selfefficacy-based education on the daily care of stroke patients, see Table 4.

Table 4.

The Effect of Self-Efficacy-Based Educationon

Daily Care in Stroke Patients,

\begin{tabular}{cll}
\hline Variable & Mean+SD & P-Value \\
\hline Daily CareBefore & $16,39+14,62$ & 0,000 \\
After & $73,19+23,57$ & \\
\hline
\end{tabular}

Based on table 4, it can be seen that there is a difference or effect of daily care before and after the educational intervention based on self-efficacy after being analyzed with the paired t-test. It is found that $\mathrm{p}$-value $=0.000<0.05$, it can be concluded that Ho is rejected, meaning that there is the effect of self-efficacy-based education on the daily care of stroke patients at Haji Adam Malik Hospital Medan. Furthermore, research conducted by S. Diz \& M. Prieto (2016), virtual reality education interventions are used in rehabilitation or physical therapy and have been shown to improve motor function in the upper limbs and improve daily activities in stroke patients.

The results of this study are in line with research conducted by Ismatika (2017), showing that there is a significant relationship between self-efficacy and daily self-care pvalue $=0.003$ istamika states that the better the client's self-efficacy, the better daily self-care. Based on the results of research obtained by Sakamoto et al (2014), suggesting about education, namely the influence of stroke education using animated cartoons and manga on elementary school children. The results of this study showed a significant increase in knowledge before the intervention $\mathrm{P}<.001$ and after the intervention $\mathrm{P}=.007$. Research by Eller et al (2016) with an analytical approach, research can guide the development of targeted interventions to increase patient self-care self-efficacy, thereby reducing costs, and helping people to achieve optimal health.

The results of this study are in line with research conducted by Sitio (2020), The results of the hypothesis test show a P value of $0.0001<0.05$, so Ho is rejected, which means that there is a difference in self-efficacy in post-stroke patients for the intervention group between before and after psychoeducation-based health education. Stroke patients also need to get counselling guidance to achieve wellness during the physical healing process. (Hsio et al., 2006; Mayerhoff, Smith, \& Schleifer, 2008). Mental health counsellors should provide guidance and counselling services in various hospitals (Mehrotra et al., 2018) because the hospital is a vital part of a comprehensive public mental health system. Not only focusing on the physical aspect, but hospitals also need to provide professional mental health personnel (counsellors) who focus on helping patients recover from the mental aspect.

Stroke causes disturbances in physical, psychological and social functioning. Most people with stroke are faced with limitations in physical, psychological and physical functioning social. Loss of mobility is a serious disorder as patients experience isolation due to loss of work and leisure activities, which can increase the risk of postdepression strokes. Self-efficacy is positively related to mobility, activities of daily living and quality of life and is negatively associated with depression. Stroke patients with high self-efficacy function better in daily activities than patients with low self-efficacy (Long et al., 2020). There are many kinds of counselling guidance activities that can be provided in hospitals to stroke patients, such as psychological assessments of patients, psychological consultation services 
for patients' families, individual counselling services for patients, and counselling services for patients' families. All these services are carried out by counsellors who are focused on one goal, namely the healing of the patient himself.

\section{Conclusions and Suggestions}

Self-efficacy-based education is effective in increasing the independence of daily selfcare for stroke patients. Education-based on self-efficacy can affect the self-care of stroke patients. The intervention in counselling guidance directs ischemic stroke patients to increase their independence in performing daily self-care. However, for further researchers, increasing the independence of daily self-care in stroke patients through counselling guidance services needs to be proven effective.

\section{References}

Amieva, H., Meillon, C., Proust-Lima, C., \& Dartigues, J. F. (2019). Is low psychomotor speed a marker of brain vulnerability in late life? Digit symbol substitution test in the prediction of Alzheimer, Parkinson, stroke, disability, and depression. Dementia and Geriatric Cognitive Disorders, 47(4-6), 297-305.

Asayesh, M. H., \& Vakili, M. (2020). Self-efficacy and identity statuses in students of Iran. Global Journal of Guidance and Counseling in Schools: Current Perspectives, 10(3), 102-109.

Brouwer-Goossensen, D., van Genugten, L., Lingsma, H. F., Dippel, D. W. J., Koudstaal, P. J., $\&$ den Hertog, H. M. (2018). Self-efficacy for health-related behaviour change in patients with TIA or minor ischemic stroke. Psychology \& Health, 33(12), 1490-1501.

Chen, Y., Wright, N., Guo, Y., Turnbull, I., Kartsonaki, C., Yang, L., Bian, Z., Pei, P., Pan, D., \& Zhang, Y. (2020). Mortality and recurrent vascular events after first incident stroke: a 9-year community-based study of 0. 5 million Chinese adults. The Lancet Global Health, 8(4), e580-e590.

Denny, M. C., Vahidy, F., Vu, K. Y. T., Sharrief, A. Z., \& Savitz, S. I. (2017). Video-based educational intervention associated with improved stroke literacy, self-efficacy, and patient satisfaction. PloS One, 12(3), e0171952.

Hachinski, V., Einhäupl, K., Ganten, D., Alladi, S., Brayne, C., Stephan, B. C. M., Sweeney, M. D., Zlokovic, B., Iturria-Medina, Y., \& Iadecola, C. (2019). Preventing dementia by preventing stroke: the Berlin Manifesto. Alzheimer's \& Dementia, 15(7), 961-984.

Kawajiri, H., Adachi, T., Kono, Y., \& Yamada, S. (2019). Development of a self-efficacy questionnaire for walking in patients with mild ischemic stroke. Journal of Stroke and Cerebrovascular Diseases, 28(2), 317-324.

Li, W., Xiao, W.-M., Chen, Y.-K., Qu, J.-F., Liu, Y.-L., Fang, X.-W., Weng, H.-Y., \& Luo, G.P. (2019). Anxiety in patients with acute ischemic stroke: risk factors and effects on 
functional status. Frontiers in Psychiatry, 10, 257.

Long, Y., Ouyang, R., \& Zhang, J. (2020). Effects of virtual reality training on occupational performance and self-efficacy of patients with stroke: a randomized controlled trial. Journal of NeuroEngineering and Rehabilitation, 17(1), 1-9.

López-Espuela, F., González-Gil, T., Amarilla-Donoso, J., Cordovilla-Guardia, S., PortillaCuenca, J. C., \& Casado-Naranjo, I. (2018). Critical points in the experience of spouse caregivers of patients who have suffered a stroke. A phenomenological interpretive study. PloS One, 13(4), e0195190.

Mairami, F. F., Warren, N., Allotey, P. A., Mak, J. S., \& Reidpath, D. D. (2020). Documenting the impact of stroke in a middle-income country: a Malaysian case study. Disability and Rehabilitation, 42(1), 102-113.

Maksimovich, I. V. (2021). Transcatheter Intracerebral Laser Photobiomodulation Therapy for Treatment of the Consequences of Ischemic Stroke with Distal Atherosclerotic Lesion. OBM Integrative and Complementary Medicine, 6(4), 1.

Mehrotra, K., Chand, P., Bandawar, M., Sagi, M. R., Kaur, S., Aurobind, G., Raj, A., Jain, S., Komaromy, M., \& Murthy, P. (2018). Effectiveness of NIMHANS ECHO blended telementoring model on Integrated Mental Health and Addiction for counsellors in rural and underserved districts of Chhattisgarh, India. Asian Journal of Psychiatry, 36, 123-127.

Müller, H. H. O., Czwalinna, K., Wang, R., Lücke, C., Lam, A. P., Philipsen, A., Gschossmann, J. M., \& Moeller, S. (2021). Occurence of Post-traumatic stress symptoms, anxiety and depression in the acute phase of transient ischemic attack and stroke. Psychiatric Quarterly, 1-11.

Ninuk, D. K., delila Rini, P., \& Erna, D. W. (2020). Relationship of family and self efficacy support to the rehabilitation motivation of stroke patients. EurAsian Journal of BioSciences Eurasia J Biosci, 14(1), 2427-2430.

Oh, H. X., De Silva, D. A., Toh, Z. A., Pikkarainen, M., Wu, V. X., \& He, H.-G. (2021). The effectiveness of self-management interventions with action-taking components in improving health-related outcomes for adult stroke survivors: a systematic review and meta-analysis. Disability and Rehabilitation, 1-16.

Rafiola, R., Setyosari, P., Radjah, C., \& Ramli, M. (2020). The Effect of Learning Motivation, Self-Efficacy, and Blended Learning on Students' Achievement in The Industrial Revolution 4.0. International Journal of Emerging Technologies in Learning (IJET), 15(8), 71-82.

Roy-O'Reilly, M., \& McCullough, L. D. (2018). Age and sex are critical factors in ischemic stroke pathology. Endocrinology, 159(8), 3120-3131.

Seneviratne, S., \& Anuruddhika, M. G. T. (n.d.). Nursing Care for Stroke. Guide to Stroke Rehabilitation for Healthcare Professionals, 44. 
Shiau, W.-L., Yuan, Y., Pu, X., Ray, S., \& Chen, C. C. (2020). Understanding fintech continuance: perspectives from self-efficacy and ECT-IS theories. Industrial Management \& Data Systems.

Szczepańska-Gieracha, J., \& Mazurek, J. (2020). The Role of Self-Efficacy in the Recovery Process of Stroke Survivors. Psychology Research and Behavior Management, 13, 897.

Torrisi, M., De Cola, M. C., Buda, A., Carioti, L., Scaltrito, M. V., Bramanti, P., Manuli, A., De Luca, R., \& Calabrò, R. S. (2018). Self-efficacy, poststroke depression, and rehabilitation outcomes: is there a correlation? Journal of Stroke and Cerebrovascular Diseases, 27(11), 3208-3211.

Volz, M., Voelkle, M. C., \& Werheid, K. (2019). General self-efficacy as a driving factor of post-stroke depression: A longitudinal study. Neuropsychological Rehabilitation, 29(9), $1426-1438$.

Wilhelm, L. O., Gellert, P., White, M., Araujo-Soares, V., Ford, G. A., Mackintosh, J. E., Rodgers, H., Sniehotta, F. F., Thomson, R. G., \& Dombrowski, S. U. (2020). The Recognition-response gap in acute stroke: examining the relationship between stroke recognition and response in a general population survey. Journal of Stroke and Cerebrovascular Diseases, 29(2), 104499.

Williams, M. L. (2021). Global warming, heat-related illnesses, and the dermatologist. International Journal of Women's Dermatology, 7(1), 70-84. 
